\title{
PERCOLAÇÃO DE POLUENTES EM SOLOS APÓS APLICAÇÃO DE RESÍDUOS DE FÁBRICA DE PAPEL RECICLADO
}

\author{
Epitágoras Oliveira Costa ${ }^{1}$, Nivaldo Eduardo Rizzi ${ }^{2}$, Helton Damin da Silva ${ }^{3}$, Shizuo Maeda ${ }^{4}$, \\ Osmir José Lavoranti ${ }^{5}$

\begin{abstract}
${ }^{1}$ Eng. Agrônomo, Dr., Volta Grande Reflorestamento, Rio Negrinho, SC, Brasil - epitagorascosta@uol.com.br ${ }^{2}$ Eng. Florestal, Dr., Depto. de Engenharia e Tecnologia Florestal, UFPR, Curitiba, PR, Brasil - niva@ufpr.br ${ }^{3}$ Eng. Florestal, Dr., EMBRAPA Florestas, Colombo, PR, Brasil - helton@cnpf.embrapa.br ${ }^{4}$ Eng. Agrônomo, Dr., EMBRAPA Florestas, Colombo, PR, Brasil - maeda@ cnpf.embrapa.br Estatístico, Dr., EMBRAPA Florestas, Colombo, PR, Brasil - osmir@cnpf.embrapa.br
\end{abstract} \\ Recebido para publicação: 17/01/2008 - Aceito para publicação: 26/09/2008
}

\begin{abstract}
Resumo
O estudo dos efeitos da aplicação de resíduos de fábrica de papel reciclado na água percolada pelo solo foi o objetivo deste trabalho. A aplicação de resíduos de fábricas de papel em solos tem sido crescente e despertado a atenção pela possibilidade de contaminação do meio ambiente, principalmente pela poluição das águas. Com o uso de resíduo de fábrica de papel reciclado, foi realizado um ensaio em casa de vegetação da Embrapa, em Colombo (PR). Foram montados tubos de PVC com mistura de resíduo e dois tipos de solo, Neossolo Regolítico Distrófico húmico e Cambissolo Húmico Distrófico tí́ico. O experimento foi realizado em blocos inteiramente casualizados, com três repetições, com dosagens crescentes $\left(0,10,20,40\right.$ e 80 t.ha $\left.^{-1}\right)$. A duração foi de 140 dias, com a coleta da água de percolação dos vasos. Os resultados foram comparados aos limites da Resolução CONAMA n ${ }^{\circ}$. 357/05. Os teores de alumínio, ferro e manganês excederam os limites da legislação. Não excederam os limites o chumbo, o cromo, os fenóis, o nitrogênio amoniacal, os nitratos, os nitritos, os ortofosfatos, o sódio e os surfactantes.

Palavras-chave: Resíduos; contaminação de águas; metais pesados; poluição; água de percolação.
\end{abstract}

\begin{abstract}
Percolated pollutants in soils after recycled paper factory residues application. Was to study the recycled paper factory residues application effects, in the percolated soils water, main objective of this work. The residues application on the soil has been crescent, and called the attention by the possibility of environment contamination, mainly by the water pollution. With the use of recycled paper factory residue, was accomplished the test at the green house from Embrapa. PVC tubes were mounted with residue mixture and two types of soil, Neossolo Regolítico Distrófico Húmico and Cambissolo Húmico Distrófico Típico. The experiment was accomplished in randomized blocks with three repetitions, with crescent dosages $\left(0,10,20,40\right.$ and 80 ton. ha $\left.{ }^{-1}\right)$. The duration was of 140 days, with the collection of the percolated water from the vases. The results were compared with the Resolution CONAMA number 357/05. The aluminum, iron and manganese exceeded the legislation limits. The chromium, phenol, amoniacal nitrogen, nitritos, orthophosphate, sodium and sufactants didn't exceed the limits.

Keywords: Residues; water contaminations; heavy metals; pollution; percolated water.
\end{abstract}

\section{INTRODUÇÃO}

A aplicação de resíduos no solo tem sido crescente e despertado atenção pela possibilidade de contaminação do meio ambiente (MELO et. al., 2002; TSUTIYA, 2006; BELLOTE et al., 1998; HARRISON et al., 2003; ANDREOLI et al., 1997).

A poluição das águas é uma das maiores preocupações quando da disposição de qualquer tipo de resíduo no solo, com os processos de lixiviação podendo atingir águas subterrâneas (LEITÃO et al., 2003; OLIVEIRA; PASQUAL, 2004), causando sérios danos ao meio ambiente. 
O Conselho Nacional do Meio Ambiente (CONAMA), pela Resolução no 357, de 17 de março de 2005, dispõe sobre a classificação dos corpos de água e estabelece diretrizes ambientais das condições e dos padrões de lançamento de efluentes (BRASIL, 2005). Em seu artigo 29, a resolução determina que a disposição de efluentes no solo não poderá causar poluição ou contaminação das águas.

$\mathrm{O}$ nitrogênio na água apresenta-se de diversas formas: como nitrato $\left(\mathrm{NO}_{3}{ }^{-}\right)$, nitrito $\left(\mathrm{NO}_{2}{ }^{-}\right)$, amônia $\left(\mathrm{NH}_{3}{ }^{+}\right)$, nitrogênio molecular $\left(\mathrm{N}_{2}{ }^{+}\right)$e nitrogênio na forma orgânica (MACEDO, 2004). Sua presença está ligada aos esgotos sanitários, efluentes industriais, escoamento das águas agrícolas, fertilizantes nitrogenados e drenagem urbana (IAP, 2005; CETESB, 2006). Alaburda; Nishihara (1998) citam os riscos do nitrogênio e seus diferentes compostos à saúde humana, pelo seu consumo através das águas de abastecimento.

O nitrogênio amoniacal possui bastante potencial de poluição nas águas, sendo um dos responsáveis pelo aparecimento de algas (CETESB, 2006; MACEDO, 2004), que contribui para os processos de eutrofização de lagos e represas (MACEDO, 2004).

Andrade; Matiazzo (2000), citando diversos autores, relatam a possibilidade de contaminação por nitratos, no solo e nas águas subterrâneas, com a utilização de resíduos contendo nitrogênio. Os nitratos $\left(\mathrm{NO}_{3}^{-}\right)$causam problemas devido à sua mobilidade, podendo poluir mananciais de água. As quantidades que o solo não tem capacidade de reter resultam em lixiviação (HARRISON et al., 2003).

$\mathrm{O}$ fósforo, mesmo sendo vital para processos biológicos, quando em excesso, combinado com altas concentrações de nitratos e nitritos, contribui para o crescimento de algas nos reservatórios e para o aumento dos processos de eutrofização das águas (BOLLMANN et. al., 2005; CETESB, 2006; MACEDO, 2004). Os valores máximos da Resolução CONAMA n ${ }^{\circ}$ 357/2005 para ortofosfatos, consideram o ambiente lêntico (água parada) e o ambiente lótico (águas continentais moventes), sendo que o valor máximo permitido para o fósforo total é de $0,1 \mathrm{mg} / \mathrm{l}$.

Normalmente, nos biossólidos, a quantidade de fósforo é menor em relação ao nitrogênio, podendo ocasionar contaminação nas águas superficiais, dependendo das quantidades a serem utilizadas (WEBBER; BATES apud TSUTIYA, 2006).

O alumínio surge na água com a presença de fluoretos, sulfatos e matéria orgânica, sendo influenciado pelo $\mathrm{pH}$ mais baixo. $\mathrm{O}$ aumento da concentração está relacionado com a turbidez da água. Os riscos ao ser humano se dão pela ingestão de alimentos e bebidas, estando associado a várias doenças. O excesso de alumínio é prejudicial às plantas (CETESB, 2006).

O bário pode ser prejudicial à saúde humana (LENNTECH, 2006). Normalmente, presente em baixas concentrações, é originário de atividades industriais (CETESB, 2006). Aparece combinado com outros elementos, sendo bastante solúvel e ativo quimicamente, podendo alcançar longas distâncias a partir do ponto de emissão.

O chumbo é citado como um dos metais presentes em diversos resíduos (TSUTIYA, 2006), como os resíduos de fábricas de papel (COSTA et al., 2002). Chega à água através das descargas de efluentes das indústrias (CETESB, 2006). Tem efeito acumulativo, causando danos ao sistema nervoso do ser humano.

Normalmente, as concentrações de cromo em água doce são baixas (CETESB, 2006). O cromo pode estar presente nas águas em sua forma hexavalente mais estável (SILVA; PEDROSO, 2001), devido principalmente aos despejos industriais (SILVA; PEDROSO, 2001), podendo causar danos ao organismo humano (MACEDO, 2004). O cromo tem baixa mobilidade no solo e dificilmente é lixiviado (SILVA; PEDROSO, 2001).

A presença de fenóis nas águas naturais normalmente é associada à poluição por atividades industriais (CETESB, 2006), como o uso de produtos desinfetantes pelas indústrias (SISINNO, 2003). São tóxicos ao ser humano e organismos aquáticos, com limites bastante restritivos para sua concentração nas águas (CETESB, 2006).

Os compostos fenólicos aparecem como subprodutos da indústria de papel, devido à presença de lignina e tanino, segundo Yabe et al. (2000). A presença de fenol pode causar distúrbios gastrointestinais, segundo Sisinno (2003). Também estão presentes na matéria orgânica do solo, surgindo durante os processos de humificação no solo (KIEHL, 1985; YABE et al., 2000).

O ferro muitas vezes ocorre associado ao manganês (MACEDO, 2004) e não é prejudicial à saúde (CETESB, 2006), porém confere à água sabor amargo e cor amarela e turva (MACEDO, 2004).

$\mathrm{Na}$ água, o manganês tem comportamento muito semelhante ao do ferro, com ocorrência mais rara (CETESB, 2006). Em excesso, pode trazer problemas neurológicos (MACEDO, 2004). As concentrações menores que $0,05 \mathrm{mg} / \mathrm{L}$ são aceitáveis em mananciais, ocorrendo em concentrações em torno de $0,2 \mathrm{mg} / \mathrm{l}$ (CETESB, 2006). 
$\mathrm{Na}$ forma líquida ou sólida, os surfactantes são utilizados em limpeza. Causam espumas, transmitem odor às águas e dificultam os processos de tratamento, podendo ser tóxicos aos peixes (BABBIT et al., 1967).

O sódio está presente nas águas naturais, sob forma de sais solúveis, geralmente com níveis abaixo de $50 \mathrm{mg} / \mathrm{L}$ (CETESB, 2006). É considerado um macronutriente essencial para os seres vivos, com bastante abundância no meio ambiente. Quando presente em altas concentrações, causa perda de permeabilidade no solo, pelo bloqueio dos poros (MELO et al., 2002).

\section{MATERIAL E MÉTODOS}

O experimento foi realizado em casa de vegetação do Centro Nacional de Pesquisa de Florestas (CNPF), da Empresa Brasileira de Pesquisa Agropecuária (EMBRAPA), em Colombo (PR). Os solos e os resíduos foram coletados em fábrica de papel higiênico da Cia. Volta Grande de Papel (CVG) em Rio Negrinho, Santa Catarina (COSTA, 2007).

Foram montados vasos com resíduos originários da centrifugação do lodo da estação de tratamento, misturados em dois tipos de solos, Neossolo Regolítico Distrófico húmico e Cambissolo Húmico Distrófico típico. Os vasos envoltos em tubo de PVC foram colocados em uma mesa a 1,20 metros do solo.

$\mathrm{Na}$ base através da mesa foi fixado um dispositivo para permitir a drenagem de água no final do experimento. A espécie Pinus taeda L. foi plantada nos vasos já preparados com solo e lodo, proporcionalmente às quantidades dos tratamentos (Figura 1). $\mathrm{O}$ delineamento experimental foi o inteiramente casualizado, com 3 repetições para 2 tipos de solo e 5 tratamentos com dosagens de resíduos $(0,10,20,40,80$ t/ha $)$.
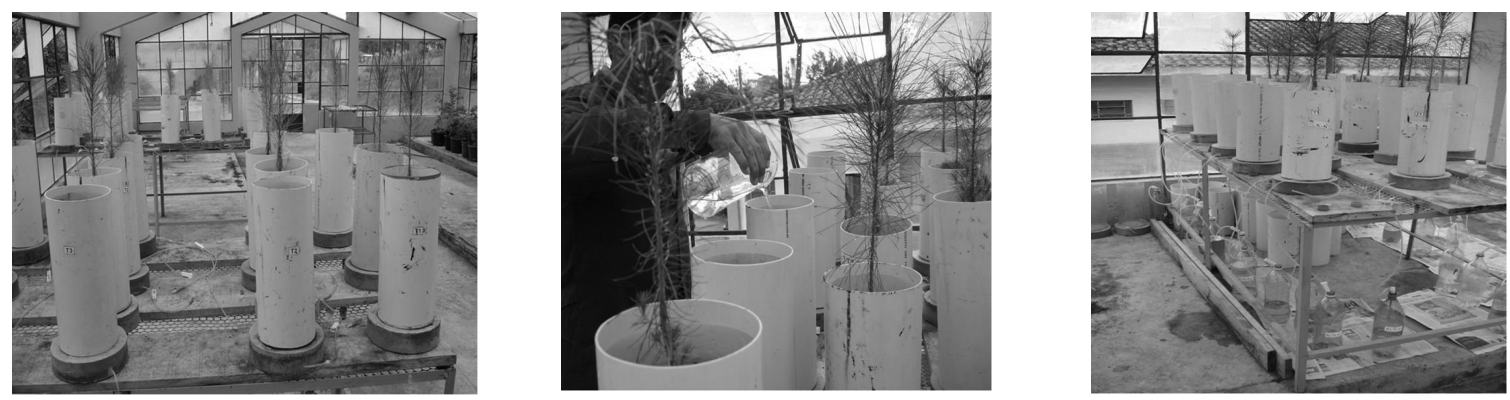

Figura 1. Vista do experimento e coleta da água de percolação.

Figure 1. Experiment view and collection of the percolated water.

O ensaio na casa de vegetação foi realizado de 04/01 a 24/05/06, com duração de 140 dias. O experimento avaliou parâmetros de qualidade de água percolada pelos vasos (objeto deste artigo), as alterações químicas do solo e o crescimento de mudas de Pinus Taeda L. plantadas nos vasos. Os solos nos vasos foram mantidos úmidos durante todo o experimento, em capacidade de campo, com irrigação periódica. No final do experimento, aplicou-se água de saturação das colunas, proporcionando fluxo de água percolada para análise dos parâmetros de qualidade de água (Figura 1). Foram coletadas amostras de água de percolação de todos os vasos para análise laboratorial da concentração de poluentes: surfactantes ou detergentes, fenóis totais, alumínio, bário, chumbo, cromo, ferro, manganês, sódio, nitrogênio amoniacal, nitrito, nitrato e ortofosfatos. Os efeitos principais e interação foram observados pelo teste $\mathrm{F}$ (MONTGOMERY, 1991). As interações significativas foram decompostas ortogonalmente.

\section{RESULTADOS E DISCUSSÃO}

A água de percolação nos dois tipos de solo apresentou os resultados constantes das tabelas 1 e 2 .

O CONAMA, através da Resolução nº 357, de 17 de março de 2005, estabeleceu as condições de lançamento de efluentes, de forma direta ou indireta, de qualquer fonte poluidora. A disposição de efluentes no solo não poderá causar poluição ou causar contaminação, capazes de causar nas águas quaisquer efeitos letais ou alteração de comportamento, reprodução ou fisiologia da vida (BRASIL, 2005). 
Tabela 1. Concentração e contrastes ortogonais de $\mathrm{Ba}, \mathrm{Pb}, \mathrm{Cr}, \mathrm{N}$ e $\mathrm{P}$ na água de percolação, em dois tipos de solo, e aplicação de diferentes quantidades de resíduos de fábrica de papel reciclado.

Table 1. Concentration and orthogonal contrasts of $\mathrm{Pb}, \mathrm{Cr}, \mathrm{N}$ and $\mathrm{P}$, in water percolate, in two kinds of soil, and application of different quantities of factory of recycled paper residues.

\begin{tabular}{|c|c|c|c|c|c|c|c|c|}
\hline \multirow[b]{2}{*}{$\begin{array}{l}\text { Tratamento } \\
\text { t/ha }\end{array}$} & \multirow[b]{2}{*}{ Tipo de solo } & \multicolumn{7}{|c|}{ Parâmetros Químicos } \\
\hline & & $\begin{array}{c}\text { Bário } \\
(\mathrm{mg} / \mathrm{L})\end{array}$ & $\begin{array}{c}\text { Chumbo } \\
\text { (mg/L) }\end{array}$ & $\begin{array}{l}\text { Cromo } \\
\text { (mg/L) }\end{array}$ & $\begin{array}{c}\text { Nitrogênio } \\
\text { amoniacal } \\
(\mathrm{mg} / \mathrm{L})\end{array}$ & $\begin{array}{c}\text { Nitratos } \\
\text { (mg/L) }\end{array}$ & $\begin{array}{c}\text { Nitritos } \\
(\mathrm{mg} / \mathrm{L})\end{array}$ & $\begin{array}{c}\text { Ortofosfatos } \\
\quad(\mathrm{mg} / \mathrm{L})\end{array}$ \\
\hline 0 & \multirow{5}{*}{ Neossolo } & 0,50 & 0,0050 & 0,0050 & 0,0367 & 1,1520 & 0,4360 & 0,0647 \\
\hline 10 & & 0,50 & 0,0050 & 0,0067 & 0,0750 & 0,9920 & 0,6880 & 0,0661 \\
\hline 20 & & 0,50 & 0,0050 & 0,0050 & 0,2061 & 0,9720 & 0,6650 & 0,0682 \\
\hline 40 & & 0,50 & 0,0050 & 0,0050 & 0,8017 & 1,0130 & 0,7440 & 0,0756 \\
\hline 80 & & 0,50 & 0,0050 & 0,0050 & 1,0533 & 1,5110 & 0,7930 & 0,0953 \\
\hline 0 & \multirow{5}{*}{ Cambissolo } & 0,50 & 0,0067 & 0,0050 & 1,1317 & 1,1370 & 0,8270 & 0,2272 \\
\hline 10 & & 0,50 & 0,0050 & 0,0050 & 1,5156 & 0,9820 & 0,8140 & 0,0932 \\
\hline 20 & & 0,50 & 0,0050 & 0,0050 & 2,1835 & 0,9860 & 0,7230 & 0,1010 \\
\hline 40 & & 0,50 & 0,0050 & 0,0050 & 2,5917 & 1,4030 & 0,7430 & 0,968 \\
\hline 80 & & 0,50 & 0,0050 & 0,0050 & 2,7390 & 1,4600 & 0,7060 & 0,0740 \\
\hline \multicolumn{2}{|c|}{ Valores de referência } & $0,70^{*}$ & $0,0010^{*}$ & $0,0050^{*}$ & $3,70^{*}$ & $10,00^{*}$ & $1,00^{*}$ & $0,10^{*}$ \\
\hline \multicolumn{2}{|c|}{ Efeitos e interações } & \multicolumn{7}{|c|}{ Valores de $\mathrm{p} * *$} \\
\hline \multicolumn{2}{|l|}{ Solos (S) } & - & $<0,0001$ & 0,3293 & $<0,0001$ & 0,39 & 0,0268 & 0,0859 \\
\hline \multicolumn{2}{|l|}{ Dose (D) } & - & $<0,0001$ & 0,4307 & $<0,0001$ & 0,0022 & 0,3083 & 0,4608 \\
\hline \multicolumn{2}{|c|}{ Interações (SxD) } & - & $<0,0001$ & 0,4307 & $<0,0001$ & 0,3447 & 0,0154 & 0,2242 \\
\hline
\end{tabular}

*: Limites da Resolução 357/2005 do CONAMA; **: Valores de p <0,01 significativo a 1\% de probabilidade pelo teste F; **: Valores de $\mathrm{p}<0,05$ significativo a $5 \%$ de probabilidade pelo teste $\mathrm{F}$.

Tabela 2. Concentração e contrastes ortogonais de $\mathrm{Al}, \mathrm{Fe}, \mathrm{Mn}$, fenóis, Na e surfactantes na água de percolação, em dois tipos de solo, e aplicação de diferentes quantidades de resíduos de fábrica de papel reciclado.

Table 2. Concentration and orthogonal contrasts of $\mathrm{Al}, \mathrm{Fe}, \mathrm{Mn}$ phenol, Na and Surfactants, in water percolate, in two kinds of soil and application of factory of recycled paper residues.

\begin{tabular}{|c|c|c|c|c|c|c|c|}
\hline \multirow{2}{*}{$\begin{array}{l}\text { Tratamento } \\
\text { t/ha }\end{array}$} & \multirow[b]{2}{*}{ Tipo de solo } & \multicolumn{6}{|c|}{ Parâmetros Químicos } \\
\hline & & $\begin{array}{c}\text { Alumínio } \\
\text { (mg/L) }\end{array}$ & $\begin{array}{l}\text { Ferro } \\
(\mathrm{mg} / \mathrm{L})\end{array}$ & $\begin{array}{c}\text { Manganês } \\
(\mathrm{mg} / \mathrm{L})\end{array}$ & $\begin{array}{l}\text { Fenóis } \\
(\mathrm{mg} / \mathrm{L})\end{array}$ & $\begin{array}{l}\text { Sódio } \\
\text { (mg/L) }\end{array}$ & $\begin{array}{c}\text { Surfactantes } \\
(\mathrm{mg} / \mathrm{L})\end{array}$ \\
\hline 0 & \multirow{5}{*}{ Neossolo } & 0,47 & 0,22 & 0,10 & 0,010 & 8,443 & 0,216 \\
\hline 10 & & 0,94 & 0,24 & 0,27 & 0,010 & 10,410 & 0,010 \\
\hline 20 & & 0,85 & 0,19 & 0,27 & 0,010 & 16,343 & 0,040 \\
\hline 40 & & 0,96 & 0,26 & 0,54 & 0,010 & 9,813 & 0,146 \\
\hline 80 & & 0,89 & 0,36 & 0,14 & 0,010 & 7,796 & 0,010 \\
\hline 0 & \multirow{5}{*}{ Cambissolo } & 0,45 & 0,20 & 0,10 & 0,010 & 8,463 & 0,020 \\
\hline 10 & & 0,53 & - & 0,10 & 0,023 & 7,966 & 0,066 \\
\hline 20 & & 0,38 & 0,31 & 0,10 & 0,010 & 7,856 & 0,046 \\
\hline 40 & & 0,45 & - & 0,10 & 0,010 & 8,143 & 0,050 \\
\hline 80 & & 0,42 & - & 0,25 & 0,020 & 8,306 & 0,046 \\
\hline \multicolumn{2}{|c|}{ Valores de referência } & $0,10^{*}$ & $0,30 *$ & $0,10^{*}$ & $0,003^{*}$ & $200 * * *$ & $0,50 *$ \\
\hline \multicolumn{2}{|c|}{ Efeitos e interações } & \multicolumn{6}{|c|}{ Valores de $\mathrm{p}^{* *}$} \\
\hline \multicolumn{2}{|l|}{ Solos (S) } & 0,0035 & - & 0,0045 & 0,0386 & 0,081 & 0,5527 \\
\hline \multirow{2}{*}{\multicolumn{2}{|c|}{$\begin{array}{l}\text { Dose (D) } \\
\text { Interac̃es (SxD) }\end{array}$}} & 0,5874 & - & 0,0535 & 0,1499 & 0,3391 & 0,5105 \\
\hline & & 0,6375 & - & 0,0070 & 0,1499 & 0,2106 & 0,1595 \\
\hline
\end{tabular}

*: Limites da Resolução 357/2005 do CONAMA; **: Valores de p <0,01 significativo a 1\% de probabilidade pelo teste F; **:Valores de $\mathrm{p}<0,05$ significativo a $5 \%$ de probabilidade pelo teste F; ***: Limites da Norma NBR 10004 da ABNT.

Assim foram definidos os critérios para se obterem os limites de valor máximo permitido de metais e outras substâncias da tabela 1 , citado no artigo 14 , referente a corpos de água de classe 1 , consideradas águas doces, destinadas ao consumo humano (BRASIL, 2005). 


\section{Bário, cromo e chumbo}

A concentração de bário, nos dois tipos de solo, em todos os tratamentos, não excedeu os limites legais permitidos pela legislação.

Para o chumbo, a análise estatística mostrou significância (valor $p=0,0001$ ) nos dois tipos de solos com as doses crescentes de resíduos. A interação mostrou efeito significativo para efeito de solo e de doses de resíduos.

Não houve aumento da concentração de cromo na água de percolação pelo uso dos resíduos de fábrica de papel. A concentração de cromo nos dois tipos de solo, em todos os tratamentos, não excedeu os limites da Resolução CONAMA n ${ }^{\circ}$ 357/2005. A análise estatística mostrou que não houve significância estatística para o contraste do efeito dos dois tipos de solos, para efeito de doses e para a interação nos mesmos.

\section{Nitrogênio amoniacal, nitratos, nitritos e ortofosfatos}

Os teores de nitrogênio total presentes nos resíduos são baixos. A água de percolação não apresentou concentrações elevadas de nitrogênio amoniacal. Os teores encontrados nos dois solos foram superiores à testemunha. Em ambos os solos, houve aumento dos teores de acordo com o incremento nas doses. Os resultados foram significativos (valor $\mathrm{p}<0,01$ ) para solos, doses e para a interação dos solos com doses (valor $\mathrm{p}<0,01$ ).

Nenhum dos teores de nitrogênio amoniacal, em ambos os solos, excederam o valor máximo da Resolução CONAMA nº 357/2005 (3,70 mg/L), conforme figura 2.
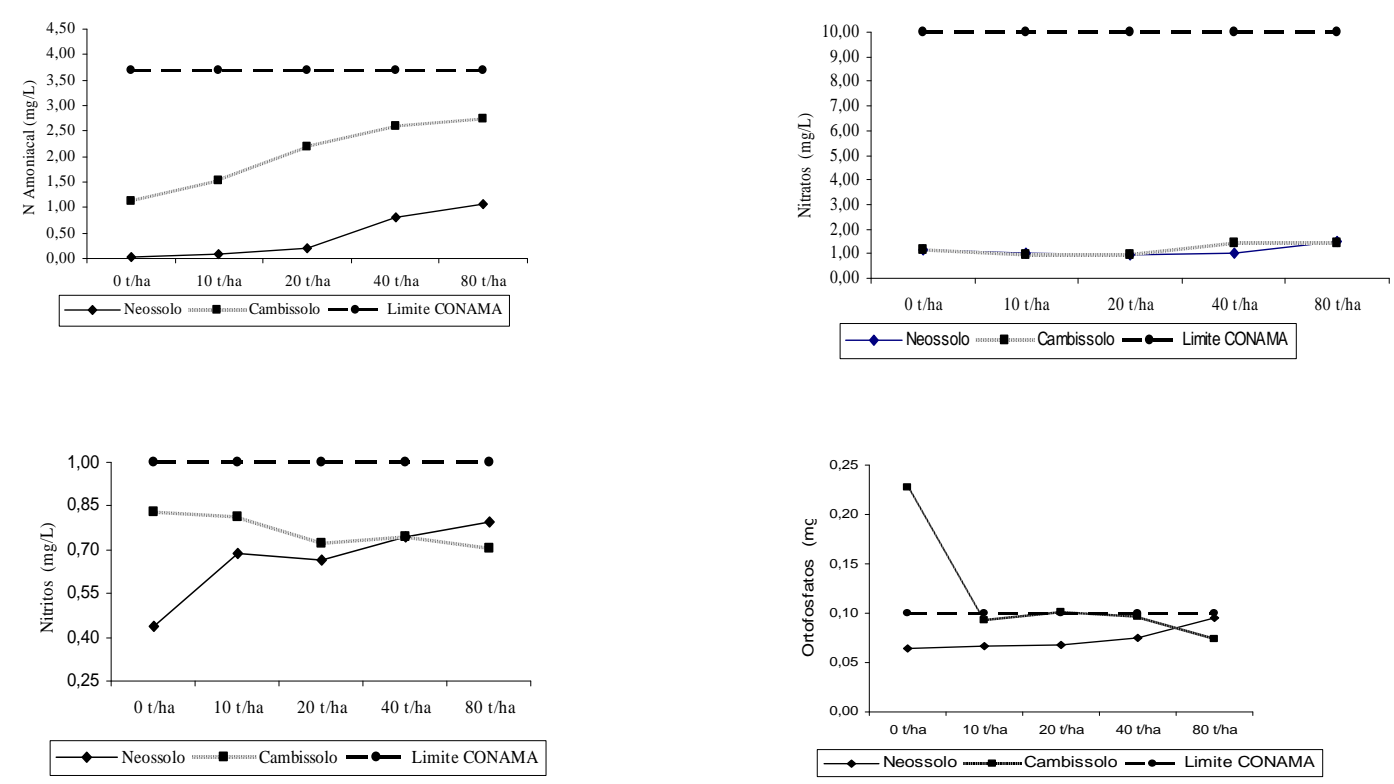

Figura 2. Teores de nitrogênio amoniacal, nitratos, nitritos e ortofosfatos na água de percolação e limites legais, em dois tipos de solos, com aplicação de diferentes doses de resíduos.

Figure 2. Nitrogen amoniacal contents, nitrates, nitritos and ortofosfatos in percolate water and legal limits, in two kinds of soils, with of different doses of residues application.

Para os nitratos, os teores encontrados na água de percolação foram muito próximos em todas as dosagens, em ambos os solos, com incrementos nas doses maiores de 40 e 80 t/ha. Por esta razão, para efeito de solos, doses e para a interação de solos e doses, encontraram-se resultados significativos (valor $p$ $<0,01)$. Nenhuma das concentrações de nitratos excedeu o valor limite da Resolução CONAMA no $357 / 2005(10 \mathrm{mg} / \mathrm{L})$.

As concentrações de nitrito (Figura 2) também não atingiram o valor máximo permitido $(1,0$ $\mathrm{mg} / \mathrm{L}$ ) pela legislação do CONAMA. No Cambissolo, os teores de nitrito da testemunha foram superiores 
a todos os tratamentos, com as concentrações decrescendo à medida que as doses de resíduos foram adicionadas ao solo. No Neossolo, ocorreu efeito contrário, com todas as dosagens superiores à testemunha e crescendo com o aumento das doses. Assim, a análise estatística foi significativa apenas para efeito de solos e para a interação solos com doses (valor $\mathrm{p}<0,05$ ).

$\mathrm{O}$ aumento da concentração de nitrogênio pode causar lixiviação (principalmente na forma de nitrato) e contaminação do lençol freático (TSUTIYA, 2006; HARRISON et al., 2003), fato não ocorrido neste experimento, com as concentrações de nitrogênio amoniacal, nitrato e nitrito dentro dos limites permitidos pela legislação.

A análise da água de percolação teve resultados distintos nos solos, para o caso dos ortofosfatos. No Neossolo, as doses de resíduos tiveram aumento mais significativo somente a partir de $40 \mathrm{t} / \mathrm{ha}$ nos teores, chegando à dose de $80 \mathrm{t} / \mathrm{ha}$, com resultado $47 \%$ superior à testemunha. No Cambissolo, a testemunha apresentou naturalmente teores elevados. A aplicação das crescentes doses de resíduos proporcionaram queda nos teores, com menor valor na dose máxima de $80 \mathrm{t} / \mathrm{ha}$.

Com isso, a análise estatística para os ortofosfatos não apresentou diferença estatística para efeito de solos e para as doses crescentes de resíduos, bem como para interação dos solos com as dosagens. As concentrações nos dois tipos de solo, com exceção da testemunha do Cambissolo, não excederam o valor máximo da Resolução CONAMA nº 357/2005 (0,10 mg/L).

\section{Alumínio, ferro e manganês}

No caso do alumínio, em todos os tratamentos com resíduo e na testemunha, foram encontrados teores relativamente altos nos dois tipos de solos, que são normalmente ácidos ( $\mathrm{pH}$ ao redor de 4,0), com concentrações superiores aos limites permitidos pela Resolução CONAMA n ${ }^{\circ} 357 / 2005$, que é de 0,10 $\mathrm{mg} / \mathrm{L}$ (Figura 3).
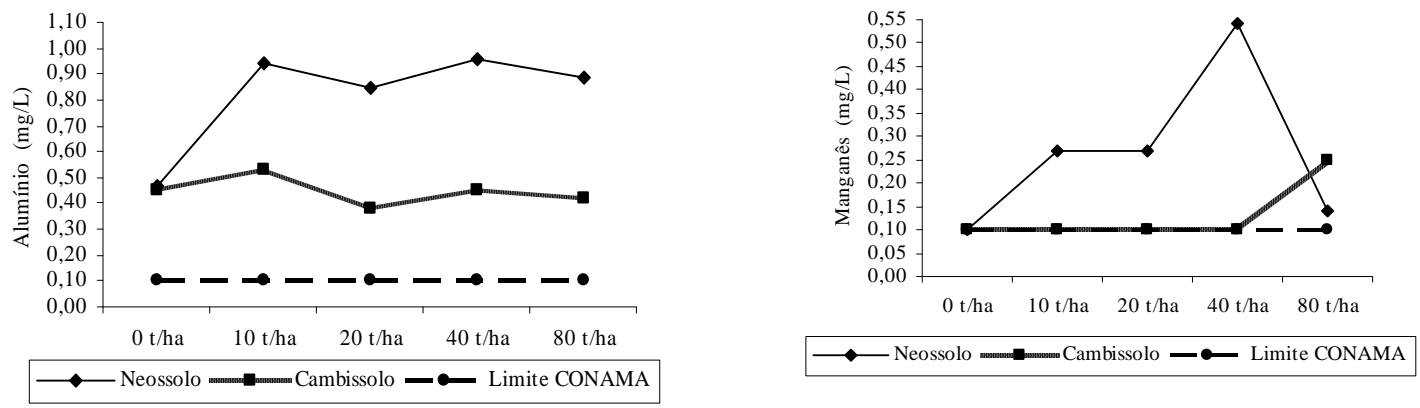

Figura 3. Teores de alumínio e manganês na água de percolação e limites legais, em dois tipos de solos, com aplicação de diferentes doses de resíduos.

Figure 3. Aluminum and manganese contents, nitrates, nitritos and ortofosfatos in percolate water and legal limits, in two kinds of soils, with of different doses of residues application.

$\mathrm{Na}$ água de percolação, o alumínio teve comportamento distinto nos dois solos. No Neossolo, as variações foram maiores em relação à testemunha, mantendo-se com pequena oscilação entre os tratamentos que receberam resíduos, todos superiores à testemunha. No Cambissolo, os teores, tiveram oscilação em relação às dosagens, com a testemunha e os tratamentos com 10 e 40 t/ha com teores superiores ao tratamento com maior dose ( $80 \mathrm{t} / \mathrm{ha})$.

Uma das possíveis razões para a ocorrência de alta concentração de alumínio na água de percolação, foi a forma de condução do experimento, em que não houve déficit de água para as plantas. Isso combinado com concentração natural de alumínio nos dois tipos de solo facilitou sua percolação. Em condições naturais, normalmente o aumento da concentração de alumínio está associado à ocorrência de chuvas (CETESB, 1999).

Deve-se também citar o uso de compostos com sulfato de alumínio na ETE para diminuição do $\mathrm{pH}$, nos processos de coagulação e floculação, que contribui para elevar a concentração do mesmo no efluente final, citado por Crespilho et al. (2004), como causador de impactos na qualidade da água no efluente final. Atualmente, buscam-se alternativas para a substituição desses produtos. A análise 
estatística para o alumínio mostrou que houve significância (valor $p=0,0035$ ) somente para efeito de solos.

As concentrações de ferro na água de percolação do resíduo de fábrica de papel reciclado, nos dois tipos de solo, mostram que na dose com 20 t/ha do Neossolo $(0,36 \mathrm{mg} / \mathrm{L})$ e na dosagem de $40 \mathrm{t} / \mathrm{ha}$ $(0,31 \mathrm{mg} / \mathrm{L})$ do Cambissolo foram superiores ao valor máximo permissível $(0,30 \mathrm{mg} / \mathrm{L})$ da Resolução CONAMA n ${ }^{\circ} 357 / 2005$. Nos tratamentos T4 e T5, houve discrepância nos resultados laboratoriais, sem possibilidade de repetição nas análises. Assim, ficou prejudicada a análise estatística e a maior discussão sobre esse elemento, que não causa toxidez ao ser humano, apenas alterações de cor e paladar na água.

Como no caso já citado do alumínio, o uso de produtos à base de cloretos, sulfatos de alumínio e ferro, produtos de uso comum na estação de tratamento de efluentes, podem influenciar o aumento da concentração de ferro nos resíduos (SISINNO, 2003).

Considerando a tabela 3 (Classe 3) para águas doces (BRASIL, 2005), da Resolução CONAMA $\mathrm{n}^{\mathrm{o}} 357 / 2005$ (5,0 mg/L), os teores de ferro encontrados na água de percolação ficam dentro de limites aceitáveis. Nessas condições, as águas podem ser destinadas ao consumo humano após tratamento convencional ou avançado.

Para o manganês, a água de percolação, nos dois solos, apresentou valores iguais ou superiores ao tratamento testemunha, em todas as doses testadas. No Cambissolo, os teores foram idênticos nas doses de $0,10,20$ e $40 \mathrm{t} / \mathrm{ha}(10 \mathrm{mg} / \mathrm{L})$. A partir daí houve uma mudança brusca na dose de $80 \mathrm{t} / \mathrm{ha}$, com diferença de $150 \%$ nos teores $(0,25 \mathrm{mg} / \mathrm{L})$. No Neossolo, houve mudanças nos teores a partir da dose de 10 t/ha, chegando ao ápice dos teores em 40 t/ha, seguido de queda acentuada na dose máxima de $80 \mathrm{t} / \mathrm{ha}$. Com essas diferenças de comportamento, não houve diferença estatística para as dosagens. Para efeito de solos e interação de solos com doses, os resultados estatísticos revelaram significância (valor $p<0,01$ ).

Em ambos os solos, a testemunha sem resíduos ficou no limite $(0,10 \mathrm{mg} / \mathrm{l})$ da Resolução CONAMA, sugerindo a presença natural do elemento no solo. No Neossolo, todos os outros tratamentos com resíduos superaram esses limites. Já no Cambissolo, somente o tratamento com a dosagem máxima (80 t/ha), superou este limite.

A resolução CONAMA n ${ }^{\circ}$ 357/2005 estabeleceu para o manganês a concentração permissível para água doce Classe I de 0,10 mg/L. Nas águas doces de Classe III, o valor máximo é de 0,50 mg/L. Tivemos concentrações acima dos limites para a Classe II de águas doces para o Neossolo nos tratamentos com 10 t/ha, 20 t/ha, 40 t/ha e 80 t/ha. Para o Cambissolo, os limites foram superados no tratamento com 80 t/ha. Se considerarmos a Classe III para águas doces, somente o tratamento com 40 t/ha do Neossolo supera o limite permissível.

O manganês tem comportamento muito semelhante ao ferro, estando associado a este, causando também alterações no sabor e coloração da água (MACEDO, 2004). Sua ocorrência em águas naturais é mais rara (CETESB, 2006), muitas vezes proveniente das rochas e do solo (MARTINS; LIMA, 2001).

Os resultados da água de percolação para os três elementos, alumínio, ferro e manganês, apresentaram concentrações acima do permitido pela legislação. No caso do ferro e do manganês, as restrições são mais de caráter estético (cor escura) e pelo sabor ruim que conferem à água, não apresentando problemas maiores de toxidez humana. Já para o alumínio, há evidências de causar danos nervosos ao ser humano (CETESB, 2006).

\section{Fenóis, sódio e surfactantes}

Os fenóis são tóxicos ao ser humano e organismos aquáticos, com limites bastante restritivos para sua concentração nas águas, como os estabelecido pela Resolução CONAMA nº 357 (0,003 mg/L).

$\mathrm{Na}$ água de percolação (Figura 4), as concentrações de fenóis em todos os tratamentos, inclusive o tratamento testemunha, excederam os limites da legislação da Resolução CONAMA. Os teores foram coincidentes na maioria dos tratamentos $(0,10 \mathrm{mg} / \mathrm{L})$, para ambos os solos, apenas com diferença em dois tratamentos do Cambissolo $(0,020 \mathrm{mg} / \mathrm{L}$ com 10 e $80 \mathrm{t} / \mathrm{ha})$. Isso repercutiu no resultado significativo somente para efeito de solos (valor $\mathrm{p}<0,05$ ).

No caso do Neossolo, todos os tratamentos, inclusive a testemunha, apresentaram teores semelhantes $(0,010 \mathrm{mg} / \mathrm{L})$ e superiores aos limites para compostos fenólicos da Resolução do CONAMA $\mathrm{n}^{\mathrm{o}} 357(0,003 \mathrm{mg} / \mathrm{l})$.

A mesma situação é encontrada no Cambissolo, onde também todos os tratamentos, inclusive a testemunha, apresentaram teores superiores ao limite da Resolução, mais elevados nos tratamentos com 10 e 80 
t/ha $(0,02 \mathrm{mg} / \mathrm{L})$. Houve diferença significativa apenas entre os dois tipos de solos $(\mathrm{p}<0,01)$, não sendo comprovada diferença estatística para as doses crescentes e a interação das doses com os tipos de solos.

Portanto, não ficou comprovada a influência dos resíduos sobre as concentrações de fenóis. A possível origem é natural, devido aos processos de degradação da matéria orgânica no solo (KIEHL, 1985; YABE et al., 2000).

Os surfactantes ou detergentes podem aparecer em concentrações mais elevadas, pelo uso de produtos de limpeza na indústria (SISINNO, 2003). O limite da Resolução nº 357/2005 para essas substâncias não foi atingido (Figura 4).
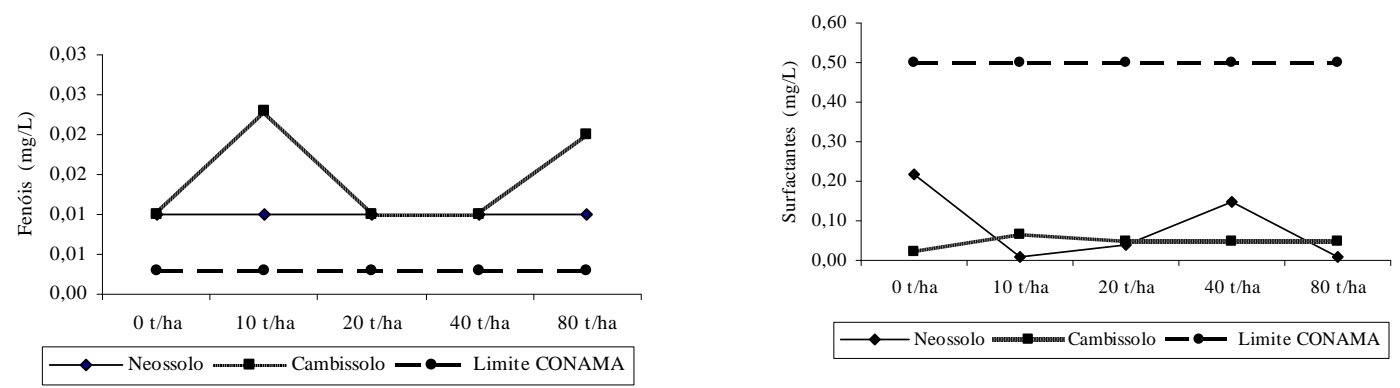

Figura 4. Teores de fenóis e surfactantes na água de percolação e limites legais, em dois tipos de solos, com aplicação de diferentes doses de resíduos.

Figure 4. Phenols and surfactantes contents, nitrates, nitritos and ortofosfatos in percolate water and legal limits, in two kinds of soils, with of different doses of residues application.

Nos dois tipos de solos, os resultados na água de percolação mostraram resultados diferenciados para cada tipo de solo. No Neossolo, os teores dos tratamentos foram menores em relação à testemunha. Efeito contrário no Cambissolo, onde todos os tratamentos foram superiores à testemunha.

Para os surfactantes, a análise estatística não revelou diferenças significativas para efeito de solos, para as doses de resíduos e para a interação dos solos com as doses. As concentrações em todos os tratamentos não excederam o valor máximo da Resolução CONAMA nº 357/2005 (0,50 mg/L).

O sódio em excesso causa perda de permeabilidade no solo, pelo bloqueio dos poros. Não consta da listagem das substâncias com limites na Resolução CONAMA no 357/2005. Assim, utilizando-se da norma $\mathrm{n}^{\circ} 10004$ da ABNT, para teste de solubilização (ABNT, 2004), com o estabelecimento do limite máximo de $200 \mathrm{mg} / \mathrm{L}$. Em ambos os solos (Figura 4), os teores encontrados são inferiores aos limites de comparação. No Cambissolo, os teores variaram pouco, com todas as dosagens inferiores à testemunha $(8,74 \mathrm{mg} / \mathrm{L})$. No Neossolo, houve maior variação, com resultados superiores à testemunha em 10,20 e 40 t/ha. O teor máximo foi atingido em $20 \mathrm{t} / \mathrm{ha}(16,34 \mathrm{mg} / \mathrm{L})$, caindo abruptamente na dose de $80 \mathrm{t} / \mathrm{ha}(7,66$ $\mathrm{mg} / \mathrm{L}$ ). Com essa disparidade, os resultados estatísticos não mostraram significância para nenhum dos efeitos estudados: solos, doses e sua interação.

\section{CONCLUSÕES}

A análise da água de percolação dos resíduos nos dois solos estudados (Neossolo e Cambissolo), observando-se os parâmetros para águas destinadas ao consumo humano (Tabela 1, classe II) da Resolução CONAMA n ${ }^{\circ} 357 / 2005$, permite as seguintes conclusões:

- Os teores de alumínio e manganês foram superiores aos valores máximos permitidos.

- Os teores de bário e chumbo não excederam os limites permitidos.

- Os teores de nitrogênio amoniacal, nitratos, nitritos, ortofosfatos e surfactantes, foram inferiores aos limites da legislação.

- Os teores de ferro também foram considerados como excedentes nos teores.

- Não ficou comprovado o aumento nos teores de fenóis e cromo pela aplicação dos resíduos.

- Os teores de sódio na água de percolação dos resíduos não excederam os limites tolerados. 


\section{REFERÊNCIAS}

ALABURDA, J.; NISHIHARA, L. Presença de nitrogênio em águas de poços. Revista da Saúde Pública, São Paulo, v. 32, n. 32, p. 160-165, abr. 1998.

ANDRADE, C. A.; MATIAZZO, M. E. nitratos e metais pesados no solo e nas árvores após aplicação de biossólido (lodo de esgoto) em plantações de Eucalyptus grandis. Scientia Florestalis, Piracicaba, n. 58, p. 59-72, dez. 2000.

ANDREOLI, C. V.; FERNANDES, F.; LARA, A. I.; BONET, B.; DOMASZAK, S. A reciclagem Agrícola de Lodo de esgoto no Estado do Paraná. In: WORKSHOP SUL-AMERICANO SOBRE USOS ALTERNATIVOS DE RESÍDUOS DE ORIGEM FLORESTAL E URBANA, 1997, Curitiba. Anais...Curitiba: Sépia, 1997. p. 83-104.

ASSOCIAÇÃO BRASILEIRA DE NORMAS TÉCNICAS (ABNT). NBR 10004: Resíduos Sólidos Classificação. Rio de Janeiro, 2004. 71 p.

BABBIT, H. E.; DOLAND, J. D.; CLEASBY, J. L. Abastecimento de água. São Paulo: E. Blücher, 1967. $592 \mathrm{p}$.

BELlOTE, A. F. J.; SILVA, H. D. da; FERREIRA, C. A.; ANDRADE, G. C. Resíduos da indústria de celulose em plantios florestais. Boletim de Pesquisa Florestal, Colombo, n. 37, p. 99-106, jul./dez. 1998.

BOLLMANN, H. A.; CARNEIRO, C.; PEGORINI, E. S. Qualidade da Água e Dinâmica de Nutrientes. In: ANDREOLI, C. V. Gestão integrada de mananciais de abastecimento eutrofizados. Curitiba: SANEPAR, 2005. p. 213-269.

BRASIL. Conselho Nacional do Meio Ambiente. Resolução n. 357, de 17 de março de 2005. Diário Oficial República Federativa do Brasil. Brasília, DF, 18 mar. 2005. Seção 1, p. 58-63.

COMPANHIA DE TECNOLOGIA DE SANEAMENTO AMBIENTAL (CETESB). Aplicação de lodos de sistemas de tratamento biológico em áreas agrícolas - critérios para projeto e operação: manual técnico, São Paulo: CETESB, 1999. 32 p.

COMPANHIA DE TECNOLOGIA DE SANEAMENTO AMBIENTAL (CETESB). Variáveis de Qualidade das Águas. 2006. Disponível em: 〈http://: www.cetesb.sp.gov.br/Agua/rios/ variaveis.asp>. Acesso em: 11/12/2006.

COSTA, E. R. O. Alterações químicas no solo e na água de percolação após aplicação de resíduos de fábrica de papel de reciclado em Pinus Taeda L. 138 f. Dissertação (Mestrado em Engenharia Florestal) Setor de Ciências Agrárias, Universidade Federal do Paraná, Curitiba, 2007.

COSTA, A. S. V. da; GALVÃO, E. R.; LOVO, I. C. FERRARI JUNIOR, M. J.; ALMEIDA, L. L.; BENEVIDES, G. Efeitos do resíduo de celulose nas características dos solos e no desenvolvimento de culturas agrícolas. In: CONGRESSO ANUAL DE CELULOSE E PAPEL, 35., 2002. São Paulo. Anais ... São Paulo: ABTCP, 2002. Disponível $>$ http://www.celuloseonline.com.br/imagembank/Docs/DocBank/dc/dc08.pdf<. Acesso em: 30/05/2007.

CRESPILHO, F. N.; SANTANA, C. G.; REZENDE, M. O. O. Tratamento de Efluente da Indústria de Processamento de Coco Utilizando Eletroflotação. Química Nova, São Paulo, v. 27, n. 3, p. 387-392, 2004.

HARRISON, R. B.; GUERRINI, I. A.; HENRY, C. L.; COLE, D. W. Reciclagem de resíduos industriais e urbanos em áreas de reflorestamento. Circular técnica, Piracicaba, n. 198, p. 1-20, jul., 2003.

INSTITUTO AMBIENTAL DO PARANÁ (IAP). Monitoramento da qualidade das águas dos rios da região Metropolitana de Curitiba no período 1992 a 2005. Curitiba, 2005.

KIEHL, E. J. Fertilizantes orgânicos. São Paulo: Agronômica Ceres, 1985. 492 p. 
LEITÃO, T. E.; FERREIRA, J. L.; OLIVEIRA, M. M.; MOINANTE, M. J. Poluição de Águas Subterrâneas: Principais Problemas, Processos de Prevenção e de Reabilitação. In: SIMPÓSIO DE HIDRÁULICA E RECURSOS HÍDRICOS DOS PAÍSES DE LÍNGUA OFICIAL PORTUGUESA, 6 , 2003, Cabo Verde. Anais... Disponível em: <http://www.dha.lnec.pt/nas/pdf/LUSBA\%20Cabo\%20 Verde_\%202003\%07\%2024.pdf> Acesso em: 20/12/2006.

LENNTECH. Bário. Disponível em: <http://:/www.lenntech.com/espanol/tabla-peiodica/Ba.html>. Acesso em: 20/12/2006.

MACEDO, J. A. B. Águas e águas. 2 ed. Belo Horizonte: CRQ-MG, 2004. 976 p.

MARTINS, I.; LIMA, I. V. Ecotoxicologia do manganês e seus Compostos. Cadernos de Referência Ambiental, Salvador, v. 7, 121p., 2001.

MELO, W. J. de; MARQUES, M. O.; MELO, V. P. de. O uso agrícola do biossólido e as propriedades do solo. In: TSUTIYA, M. T.; COMPARINI, J. B.; SOBRINHO, P. A.; HESPANHOL, I.; CARVALHO, P. C. T.; MELFI, A. J. MELO, W. J.; MARQUES, M. O. Biossólidos na agricultura. 2. ed. São Paulo: ABES, 2002. p. 289-359.

MONTGOMERY, D. C. Design and analysis of experiments. 3. ed. New York: J.Wiley, 1991. 649 p.

OLIVEIRA, S.; PASQUAL, A. Avaliação de parâmetros indicadores de poluição por efluente líquido de um aterro sanitário. Engenharia Sanitária Ambiental, Rio de Janeiro, v. 9, n. 3, p. 240-249, 2004.

SILVA, C. S.; PEDROZO, M. de F. Ecotoxicologia do cromo e seus compostos. Cadernos de Referência Ambiental, Salvador, v. 5, 100 p., 2001.

SISINNO, C. L. S. Disposição em Aterros Controlados de Resíduos Sólidos Industriais não-inertes: Avaliação dos Componentes Tóxicos e Implicações para o Ambiente e para a Saúde Humana. Caderno de Saúde Pública, Rio de Janeiro, v. 19. n. 2, p. 369-374, mar./abr. 2003.

TSUTIYA, M. T. Limites de Metais Pesados em Biossólidos para Uso Agrícola Proposta para a Regulamentação Federal e Estadual. Disponível em: <http://www.aesabesp.com.br/encontro_exemplo_ 2006.pdf.>. Acesso em: 20/12/2006.

YABE, M. J. S.; GIMENEZ, S. M. N.; BISINOTI, C.; PAES, M. A. A.; LOBO, R. R.; FIGUEIREDO, E. S. Influência de fenóis da bacia do Rio Tibagi. In: Reunião Anual da Sociedade Brasileira de Química, 23., 2000, Poços de Caldas. Anais... Disponível em: <http://www.sbq.org.br/ranteriores/23/resumos/1260/ index.html> Acesso em: 12/03/2007. 